\title{
Lockeans versus Nationalists on Territorial Rights.
}

\section{David Miller}

Nuffield College, University of Oxford, UK

\begin{abstract}
This article examines John Simmons' Lockean theory of territorial rights, and defends the superiority of the rival nationalist theory that he rejects. It begins by arguing that all philosophical accounts of territory need to be supplemented by non-ideal theory to address real-world territorial conflicts. Turning to the Lockean theory, it points out that if territorial rights are to emerge from individual property rights in land, such rights must be robust. But on Simmons' account, individuals only have natural property rights in material things involved in their ongoing purposive activities. Thus a state founded on such rights would be vulnerable to having neglected parts of its territory expropriated by outsiders. It might also have to downsize in response to population increases elsewhere. Nationalist theories base territorial rights on the collective occupation and transformation of land by groups with shared identities. Three charges against such theories are rebutted: 1) The idea of cohesive national cultures is a myth, in the face of internal cultural diversity. 2) Despite their appeal to history, nationalist theories privilege current possessors of land at the expense of the dispossessed. 3) Such theories cannot solve the problem of 'trapped minorities' who don't share the national identity of the majority.
\end{abstract}

\section{Keywords}

territory, property, Locke, nationalism, non-ideal theory

I

In this essay, I examine John Simmons' attempt in Boundaries of Authority to develop a Lockean theory of state legitimacy and territorial rights. ${ }^{1}$ This book is an impressive addition to the growing body of philosophical literature on territory: its central insight is that to justify a state's claim to jurisdiction over a territory, one must investigate the historical process whereby it came to exercise such jurisdiction, and this sets it apart from 'functionalist' theories of territory, which try to derive territorial rights from states' current performance of functions such as protecting basic rights and delivering justice. The book offers a deep critique of such theories, arguing in particular that they are unable to solve the 
'boundary problem' - the problem of demarcating the particular territory over which jurisdiction can legitimately be exercised. On this issue, my sympathies are firmly with Simmons against the functionalists. ${ }^{2}$ But among theories of territory that are sensitive to history, Lockean accounts, which start from individual property holdings, compete with nationalist accounts, which attribute territorial rights collectively to the group that has occupied, developed and/or become attached to areas of land. ${ }^{3}$ So it is also part of Simmons' aim to critique nationalist theories of this kind, and to show that a Lockean account does a better job of explaining when states' territorial claims are justified.

Locke himself believed that by locating the origins of (non-tyrannical) government in the consent of those who held property in the region over which the government claimed authority, he could legitimate at least some contemporary states (such as the England of his day). His recent followers have doubted that this could be done. Either they have been anarchists, or quasi-anarchists, holding that the requirement of consent means that individuals subject to government may at any time withdraw their allegiance and return to the state of nature (see e.g. Nozick, 1974; Steiner, 1996); or they have been what Simmons calls 'plebiscitary voluntarists', who believe that the inhabitants of any region within the state are permitted to secede by a majority vote taken within that area, so long as they also permit internal minorities to exercise the same right (see e.g. Beran, 1984; Altman and Wellman, 2009, ch. 3). Simmons wants to show that political authority can be built on firmer foundations than this. But at the same time, he is perfectly willing to concede that there are few if any contemporary states with the kind of clean pedigree that would allow us to judge them fully legitimate. So he sees the need for 'non-ideal theory' to provide guidance in a world that falls significantly short of the requirements of the ideal.

I therefore begin my commentary with a brief discussion of the ideal/non-ideal distinction, and how it is employed in the book. I then move on to Simmons' Lockean theory of property rights, and ask whether these rights are robust enough to support states' territorial claims. Finally I examine Simmons' critique of nationalist theories and propose some responses that nationalists can offer. 
The distinction between ideal and non-ideal political theory has been drawn in several different ways in recent political philosophy (see Valentini, 2012), but Simmons takes his lead from Rawls (see also Simmons, 2010). On this view, ideal theory sets out the principles that would delineate a fully just society, assuming full compliance with these principles on the part of its members, and favourable conditions for implementing them; whereas nonideal theory provides critical tools for assessing societies that fall short of this ideal, and also transitional guidance concerning how best to move towards it starting from where we are now. Although there are complications caused by the fact that the path towards the ideal, assuming we can identify one, may involve interim periods in which injustice increases, it makes sense for Rawls to call for non-ideal theory, because the just state for him is defined by structural features that existing states can approximate to a greater or lesser degree. For example, we could look to see whether proposed changes to our institutions would bring us closer to, or further away from, realising the ideal of fair equality of opportunity. In contrast, it might seem that a Lockean theory of the kind that Simmons defends has no place for non-ideal theory, since if an existing state has gained its authority and its territory by means that breach the relevant principles, we cannot rewind the past to get closer to the state of affairs that might have obtained had the breaches not occurred - not least because we have no way of identifying that state of affairs. For example, we cannot say whether in a hypothetical past in which states had all been brought into existence by the agreement of (just) property-owners, there would even be states that we could recognize as corresponding to today's France or Canada (perhaps there would only be city-republics). We can of course sometimes identify victims of past wrongdoing, and we may be able to offer them (or their descendants) something by way of compensation, but this is not an application of 'non-ideal theory' in Rawls' sense. Simmons does suggest ways of diluting state sovereignty that he believes would bring us closer to the political arrangements that might qualify as fully legitimate, but he is aware of how little guidance this will provide in concrete cases. As he says

Given the long human history of injustice with respect to land, both by individuals and by states, along with the controversial nature of even many respectable claims to property, we simply cannot expect to be able to untangle the various strands of entitlement to lands in a way that can illuminate any actual territorial disputes (130). 
Following from this, there are moments in the book where Simmons suggests that non-ideal theory might have to follow the path that his Rawlsian and Kantian opponents advocate, by taking 'domestic egalitarian reform' as its first priority, and leaving 'redressing past wrongs of subjection' until a new international order is in place (90).

But the general moral I want to draw out of this discussion is that any philosophical theory that seeks to establish foundational principles for territorial rights, whatever its exact shape, will need to be supplemented if it is going to provide practical advice on real-world issues of contested territory. When the ideal cannot be implemented in full, whether as a result of past injustice or for some other reason, we have to be able to identify feasible alternatives that represent reasonable trade-offs between the principles that define the ideal, and that do not block further improvements in future. By recognizing the need for non-ideal theory, Simmons cuts himself some slack in this area, but he seems unwilling to allow the same to rival theories. Surely they too must be permitted to propose compromise solutions in cases where the ideal is out of reach for practical reasons. What's sauce for the goose must be sauce for the gander. So if functionalist or nationalist theories run into problems when applied to the real world, they too must be allowed to say 'here we need some non-ideal theory'. I return to this issue later in the essay.

III

Let me now look more closely at the Lockean theory of territory itself. In Simmons' presentation, its two main pillars are property rights and consent to government. A legitimate state is formed when the rightful holders of land in a given area consent to transfer jurisdiction over that land to a political authority, and the extent of its territory is the extent of the landholdings of the consenters, understood in the main to be private property, but with allowance made for some land to be held in common within the boundaries of the state. I will leave aside the practical problems that would need to be resolved for this to happen (for example, how to deal with dissenters who do not want to be ruled by the authority that is created). ${ }^{4}$ The issue of principle I will focus on is whether people can enjoy sufficiently strong rights of property prior to the institution of the state to ground its territorial claims. For if we only encounter strong property rights once political jurisdiction has been established, then the theory is in danger of becoming circular: we 
would need to know that the state has rightful jurisdiction over a territory before we could say that the people inhabiting the territory had morally robust landholdings, but then it's those landholdings we need to appeal to in order to establish, via the giving of consent, that the state's jurisdiction is legitimate.

The question, therefore, is whether a Lockean political philosophy can yield a justification of pre-political property rights in land that are sufficiently robust to ground the state's claim to territorial jurisdiction. ${ }^{5}$ Simmons makes it clear that not all the conventional incidents of property can be justified in this way. Prior to the enactment of positive law by the state, all that can be defended is a pared down version which assures the property-owner just enough control over the object owned to serve the purposes for which private ownership is needed. Simmons has developed his interpretation of Locke's theory of property most fully in an earlier book, The Lockean Theory of Rights (Simmons, 1992). On this account, it is centrally the interest in personal self-government that justifies property: we need to be able to use and manage physical objects in order to carry out most of our aims and projects. But this justifying feature also sets limits to what we claim. As he acknowledges:

One may only have property in what has been made a part and continues to be a part of one's purposive activities. We can make property only in what is actually labored on and continues to be used in our projects; what is spoiled, wasted, or lying unused is not anyone's property, but returns to (or remains) common (Simmons, 1992: 276).

There is also a second limit on property-holding that I will return to shortly. In Boundaries of Authority, Simmons continues to appeal to involvement in a person's 'projects and purposive activities' as the grounds on which objects can be acquired as property. But he now argues, in addition, that once acquired, they continued to be owned unless deliberately abandoned by the right-holder. In his discussion of 'rights supersession' (ch.7) he attacks the idea (defended particularly in Waldron, 1992) that my property rights can be superseded by other people coming to make things that were originally mine central to their own plans and purposes. He speaks of the person who, in Lockean parlance, first 'mixes their labour' with an object as 'marking' that object in such a way that it continues to be theirs, even if later on they cease to have any further interest in it (163). But what is the moral basis for this practice of permanent retention? Why is it anything more than a 
convention, like the convention that the first person to put their beach towel on the sun lounger in the morning has the right to monopolise the lounger for the rest of the day, even if he is currently not using it? Of course, under the legal systems we are familiar with, property rights once acquired are understood to be stable over the long term, subject only to minor qualifications such as are imposed by the doctrine of adverse possession. But if, like Simmons' Locke, you think that ownership is justified by productive use of an object, it's not clear why if Jane begins to incorporate object $\mathrm{O}$ into her projects while it becomes peripheral to Peter's, Jane shouldn't after a time be able to claim $\mathrm{O}$ as rightfully hers, superseding Peter's earlier claim. Why, morally speaking, should there such an asymmetry between the conditions under which property is originally acquired and the conditions under which it is retained?

The relevance of this to the territory question is that Lockean pre-political property rights (as understood by Simmons) don't seem robust enough to underwrite stable territorial rights. Landowners who neglect their estate are liable to be displaced by incomers who can make more productive use of it, and these new arrivals may well not consent to the political authority already established in that place. Simmons follows Locke in assuming that when property-owners who have given their consent to government transfer their holdings to someone else, the recipient acquires the property encumbered by the requirement to give consent to the same authority. But the case I am envisaging is not one of voluntary transfer, but of newcomers displacing idle landowners - coming in and taking possession of land that is no longer being used for any productive purpose and mixing their labour with it. Since as outsiders they are not yet subject to the state's authority, they are constrained only by the moral rights of the previous owners - and these appear not to generate any obligation to refrain from taking objects that are no longer involved in someone else's purposive activities. ${ }^{6}$ Because of this possibility of involuntary displacement, the problem of how to form a continuous state with regular boundaries, rather than something that looks more like a Swiss cheese, is not just a one-off problem that once solved is solved in perpetuity. To protect the territorial claims of the state, all of the citizens who have given their consent would need to continue interacting with their landed property with sufficient enthusiasm to ward off the threat of outside encroachment. In a Simmons-Lockean world, the World War II slogan 'Dig for Britain' which was used to encourage people to turn their gardens into 
allotments to produce home-grown food would carry a new meaning: keep on digging if you don't want your country to be dismembered by outsiders with better claims to its land.

Simmons might be tempted to reply here that once the state has established territorial rights, it can protect its citizens from dispossession by enforcing their landownership rights against outsiders even when they are no longer actively using the land in question. But on what basis can it do this? Simmons suggests that individual landowners, and the state they have consented to, between them share 'the strong ownership rights over land which individuals may naturally acquire by their labor' (240). But as we have seen, the ownership rights that individuals acquire by nature are rather weak (on Simmons' view), extending only to 'what has been made a part and continues to be a part of one's purposive activities'.7 Strong ownership rights, which allow individuals to retain control over objects that are no longer implicated in their purposive activities, are creatures of the state. But the corresponding obligations - such as not interfering with the property of others even if it seems that they are no longer using it productively - apply only among those who, through their consent, have authorised the state to create and enforce stronger, better-defined, property rights. They do not apply to strangers who were not party to the social contract.

IV

But perhaps Simmons would be less worried that I am that his version of Lockean theory fails to generate strong rights to territory, including rights to prevent outsiders taking over unused property. For he is quite explicit that the rights his theory can justify are less stable than those we normally assume states possess. This is due to a second limitation on Lockean property rights: the requirement that one cannot appropriate more than one's fair share of the global commons. As Simmons puts it:

Persons have rights of fair access to available land and natural resources. These rights are opportunity rights to, not rights of property in, a fair share of the earth. Property rights in the earth and its resources are acquired by the incorporation of things (that fall within our fair shares) into our legitimate purposive activities. But changes in circumstances may change what constitutes a fair share (181). 
The implication is that states may in some circumstances have to downsize their territorial claims in order to grant these rights of fair access to outsiders.

Simmons is less explicit about what 'fair access' means here. One could interpret it either in egalitarian terms or in terms of sufficiency. The egalitarian reading would hold that each person must have as extensive an opportunity as every other to acquire natural resources. In his earlier work on Locke, Simmons makes it clear that this was indeed Locke's own view (Simmons, 1992: 288-98). In the state of nature, a person could only appropriate property on condition that others had access to equally productive land and other resources. This limitation could only be overcome by universal consent, which occurs when money is introduced - Locke's assumption being that those who are no longer able to appropriate are sufficiently compensated by participating in a commercial economy that provides them with adequate resources for an independent life. But if we apply this reasoning to the state's territorial rights, it has radical implications. For a state to claim territorial jurisdiction rightfully, it would need to show that the combined property-holdings of its subjects did not add up to a greater-than-equal share of the total usable surface of the earth. Alternatively, it would need to show that outsiders who together have a less-than-equal share have consented to the inequality. But how could this be shown? Whatever the merits of Locke's claim about the use of money implying consent to unequal appropriation (and Simmons (1992: 303-304) expresses serious doubts about that claim), it applies within a state, not between states. So the egalitarian reading of the Lockean constraint on appropriation would potentially have highly destabilising implications for the existing system of states and its associated pattern of territorial holdings.

One might try to avoid this conclusion by substituting a sufficiency constraint for the equality constraint on appropriation. On this more conservative reading, 'fair access' would mean 'sufficient access to land and natural resources for a person to lead a minimally decent life'. This, however, would be a significant departure from Locke, and it calls out for justification. If $A$ and $B$ are the only inhabitants of an island, and $A$ proceeds to appropriate the lion's share of productive land, leaving B just enough to sustain herself, we are bound to ask what entitles A to do this. A needs to justify his unequal share by appeal to some relevant feature such as his ability to make better use of the land, or by showing that the 
inequality works in B's favour too. Merely to grab the land as first occupier and then point out that B has been left 'enough' will not do.

Notice too that even on this weaker reading of the fair access condition, there may be cases in which apparently legitimate states will be obliged to downsize their territory. Why might this happen? The most obvious scenario is external population growth, and Simmons works through the question of what permissible downsizing involves by taking the example of an island where the arrival of newcomers obliges the original inhabitants to scale back their existing landholdings (181-185). But I find it somewhat puzzling that population increases beyond state borders could justify requiring an otherwise legitimate state to give up some of the territory it currently holds, regardless of why those increases are occurring. Population growth is not simply a fact of nature that states are unable to control. Although it may to some extent reflect cultural values and practices that are difficult to change in the short run, states can license the sale of contraceptives (or provide them free of charge), fund family planning clinics, financially incentivise having fewer children, and so forth; so allowing a state to increase its population and then demand land transfers from other states in the name of fair access looks like a classic case of a negative externality that cannot justifiably be imposed on outsiders. In an already crowded world, legitimate states have a duty to ensure that their populations do not increase beyond the size they are able to sustain through direct or indirect (via trade) use of their resources. To object to such a duty, you would need to believe in something like a natural right to unlimited procreation. All of this is consistent with recognizing that there might be other cases in which some territorial downsizing is required, such as when land is rendered uninhabitable by pollution or rising sea levels for which the occupants are not responsible, so that their basic rights can only be protected by providing them with access to the territory of another state.

\section{V}

Even on the sufficiency reading of 'fair access', then, Simmons' theory of territory may fail to protect legitimate states from having to downsize in response to predicaments (like excessive population growth) for which other states can be held responsible. Does it matter that, in Simmons' hands, the Lockean theory appears unable to justify robust territorial rights? For those who find this an unwelcome conclusion, the nationalist theory of territory 
may seem to offer an attractive alternative. According to this view, states can claim territorial rights when they represent groups with legitimate claims to the land over which the state exercises jurisdiction. And groups can make such claims when they occupy land collectively over time, endowing it with value either through transforming it materially to better serves the group's needs or interests, or through the symbolic significance it acquires by virtue of the events that have occurred there or the role that it plays in the groups' culture. In either or both of these ways, the group in question establishes a connection to the land which gives it a strong claim both to remain in occupation and to exercise control over the way that the land is used. ${ }^{8}$ Note that although it makes sense to call this a 'nationalist' theory of territory by virtue of the fact that the groups that can make such a claim, on a large scale, are almost certainly be going to be nations, the argument itself applies to any group that can demonstrate a connection to land of the right sort. So the theory is also hospitable to the claims of indigenous groups, and indeed to small, territorially concentrated groups of other kinds that can demonstrate a strong interest in controlling the land they occupy.

Quite reasonably, however, Simmons limits his critique of the theory to the case of nations stricto sensu. His reasons for rejecting the nationalist theory essentially boil down to three (104-108, 140-145, 235-238): ${ }^{9}$

1) He is sceptical of the idea of nations as groups with shared cultures, where the embodiment of culture in territory is presented as one of grounds for granting nations rights in the territory in question;

2) He argues that, despite their appeal to history as a second ground for territorial rights, nationalist theories end up endorsing the claims of present possessors and dismissing the claims of colonised and other dispossessed minorities;

3) He claims that nationalist theories ignore the problem of 'trapped minorities' - groups located within the state who don't share the majority identity and who wish to practice selfdetermination separately;

I will respond to each of these arguments in turn. 
1. It is not wrong to describe a nation as a cultural group, but if we do so we need to be clear about what we mean by a national culture. Any nationalist theory intended to be applicable to a modern liberal society will need to make a distinction between public and private culture. In the latter realm, compatriots can be expected to hold wildly different views about what is valuable or how life should be lived: sports fans will confront aesthetes, meat-eaters will confront vegans, evangelicals will confront militant atheists, and so forth. So if there is going to be cultural convergence, it must occur at a different level. Simmons suggests that in liberal societies public cultures will all look much the same, composed of political commitments to human rights, democratic procedures, and so forth (237). But this is misleading in several respects. First, for historical and institutional reasons, even narrowly political values such as democracy are understood differently in each national culture. Both France and the U.S. count in some broad sense as democracies, but it is plain that the French and the Americans have quite different understandings of what it means for a state to be democratic. Second, an important aspect of public culture is a national narrative which tells a story about the nation came into being, how it has behaved in the past, what responsibilities it bears as a result, what its present role in the world should be, and so forth. Such narratives change gradually over time as part of broader changes in the public culture, but they are nonetheless unique to each people, and have a strong, though often unacknowledged, influence on the collective decisions that are taken over time. Third, there will at any moment be a working agreement on which public goods the state will promote and in what proportions: how far it should put its available resources into developing economic infrastructure, preserving historic buildings, promoting the arts, constructing sports arenas, integrating minority groups, protecting the natural environment, etc., etc. Individual members will of course value these goods differently; but we can still speak of a public shared culture, because there will be broad agreement, first, that these are common goals that the society should pursue, and second, at any time, over roughly how they should be balanced against one another. In this respect, again, each nation is uniquethough some will have public cultures that are more alike than others.

All of this goes merely to show that nations, considered as groups defined in part by their shared public cultures, are real. It does not yet show how being a nation entitles you to the land that you currently occupy. This brings us to the second problem raised by Simmons. 
2. Few nations have 'immaculate' histories whereby the people who now occupy territory are descended directly from an original group who settled on unoccupied land. The usual story is one of conquest and absorption of the natives, or more rarely expulsion. How do these past facts bear on present-day territorial rights? Here we need to distinguish between different cases. If the original inhabitants have wholly assimilated to their erstwhile conquerors, creating together over time a shared national identity, no problem arises. No one any longer suggests (or could reasonably argue) that England rightfully belongs to the Anglo-Saxons (or indeed even their predecessors, the Celts?) who were conquered and dispossessed by the Normans. Where assimilation is only partial, however, and an indigenous group remains on its historic territory, then we have national minorities such as we find in several European states (Catalans, Scots, South Tyroleans) and the solution recommended by the nationalist theory is to grant partial self-government rights to those minorities. I return to the question of justified secession later, but an overarching nation's territorial rights are not invalidated by the mere fact that it includes minority groups who were originally incorporated involuntarily, so long as their self-determination rights are protected - that is, they are allowed to exercise a significant degree of control over the territory that is historically theirs. But then we come to the case that I believe mainly exercises Simmons, where indigenous groups have been deprived of the territory to which on historical grounds they had a valid title, by being relocated elsewhere or squashed into a small part of their original domain.

Assuming that this domain cannot simply be restored, for the reason that it has been occupied by incomers who have developed it to suit their own interests and cultural values, we have two rival claims of the same general type to the land in question - claims typically based on some combination of occupancy, productive use, and symbolic significance. Should we say that the present-day claims of the incoming group count for nothing because their predecessors' original act of occupation was illegitimate? This seems an extreme conclusion to draw, bearing in mind that the current occupiers will very likely be innocent beneficiaries of their ancestors' wrongdoing. They may well owe compensation to the dispossessed, but must they wholly abandon their territorial claims? It seems that we face a conflict of rights, and it's just not clear why 'first possession' should count for so much that it must outweigh all subsequent claims. ${ }^{10}$ 
It's at this point that the distinction between ideal and non-ideal theory comes into play. We need a nationalist version of non-ideal theory to guide us towards the solution that best approximates an ideal world in which everyone's valid territorial claims are met. It seems likely that some form of identity-transformation will be required in the third case l've outlined, and so there will be questions about what means can legitimately be employed to bring this about, which identify shifts will be least costly for those who have to make them, and so forth. There can be large scale nation-building, but there can also be forms of multiculturalism that give special weight to the needs and interests of wrongfully colonised indigenous groups.

3. We turn next to the problem of what to do about so-called 'trapped minorities'. These are groups who have occupancy rights within the territory of the state, but who do not wish to be governed by it - they would prefer some other arrangement (say to be independent, or to join another state). This may have come about because the group's ancestors were incorporated into the state against their will, and continuing cultural differences or political disagreements mean that the group's members feel excluded from the national culture. But we can also imagine cases in which, without any initial failure of consent, one part of the society - say a religious minority - develops in such a way that it becomes increasingly alienated from the majority and its political decisions. A question then arises as to whether the remainder nation can continue to enjoy full territorial rights, or whether they must allow trapped minorities to dismember the state, for example by seceding and taking part of the territory with them.

For a nationalist, this again calls for non-ideal theory. What is needed in such instances is to find a political solution that allows each relevant group to enjoy an adequate measure of self-determination, and the form the solution takes will depend upon the details of the case. For example, sometimes we will find 'nested nations', as may perhaps be illustrated by the example of Catalonia and Spain, where within the sub-region most people have split-level political identities, seeing themselves as belonging both to the larger inclusive nation and to the smaller geographical region (which some may regard as a nation in its own right). Here, the constitutional settlement that best respects these mixed identities and the aspirations to political autonomy that they embody will be one that guarantees the sub-nation significant rights of self-government. In other cases the relationship between the two 
groups will be one of active hostility, and in that case secession may be the best option, provided that both the seceding state and the remainder state can be territorially configured in such a way that they can each enjoy genuine self-determination, and provided also that the problem of trapped minorities does not simply recur in a more virulent form in one or both of units that are created. In other cases still, it may be necessary to create a semi-autonomous region over which two neighbouring states both enjoy partial sovereignty. ${ }^{11}$

This is not the place to spell out in greater detail how a nationalist theory of territory will handle cases of alienated internal minorities. Whatever the difficulties, however, it's far from clear that the Lockean theory is any better placed to deal with them. Simmons rules out voluntarism, where anyone is entitled to propose a plebiscite in a bounded geographical area to decide whether that area should become an independent unit (110-115). But he does not say much about how his own Lockean theory would deal with secessionist claims, apart from one footnote very near to the end of the book, where he says that consent to the state's authority requires periodic reaffirmation, so that where the binding force of previously given consent lapses, secession may be permissible (246). One would like to hear a lot more about how this is supposed to work - for example, who decides when consent has lapsed? Is a majority vote for independence on one occasion sufficient evidence? And how are the prospective secessionists going to avoid taking unwilling, property-owning individuals with them? The footnote proposes as a condition for a permissible secession that there should be 'no newly trapped minorities or individuals' (my emphasis) in the seceding territory, from which it appears that any holdouts who cannot be persuaded either to offer their consent or to emigrate will be able to block the secession. The antimajoritarian animus that makes the problem of trapped minorities so urgent in the first place seems also to prevent the problem being solved by secession, except in the unlikely event that there is unanimous agreement to it in the seceding region, or all the dissenters are willing to be bought out.

VI

So, to conclude, I agree with Simmons that if we want to have a philosophical account of territory that does more than show, in general terms, how a legitimate territorial state is 
possible, we have to look beyond utilitarian or neo-Kantian functionalist theories. We have to pay attention to the historical processes whereby particular territorial claims can be established. But to begin with individual property-holdings is to look in the wrong place. Unlike property, territory is an inherently collective phenomenon. Whatever share in territorial rights we have as individuals, we gain through our tribes.

Simmons might respond that this leaves the individual too much at the mercy of the tribe. But the collectivist view of territory can be combined with a liberal theory of the state that grants each person an entrenched set of rights, including rights to own property, to protect their freedom. All that it denies is that people may use these rights to dismember the state by withdrawing land and creating new territorial boundaries. They have, or course, a right of individual exit, taking their moveable assets with them. But if any boundary-redrawing is going to occur, it must be at the behest of a group that can show, collectively, that they have stronger territorial claims to the land in question than its current possessors. They must be able to demonstrate their capacity to form an independent political unit, and they must show that their relationship to the land is special, and separable from that of the wider group from which they are seeking a divorce.

\section{Acknowledgements}

An earlier version of this article was presented to the conference on 'Territorial Rights: New Directions and Challenges', organized by Amandine Catala and Margaret Moore at the Université du Québec à Montréal, April 21-22, 2017. I am grateful to the participants for their comments and especially to the editors and referees for this journal for their detailed advice.

\section{Notes}

${ }^{1}$ Simmons (2016). Page references in the text are to this work.

${ }^{2}$ For leading functionalist theories of territory, see Waldron (1993), Waldron (2010), Stilz (2009), Stilz (2011), and Ypi (2014). For my critique of such theories, see Miller (2016). 
${ }^{3}$ Prominent nationalist theories of territory include Gans (2002), ch. 4, Meisels (2009) and Miller (2012). Among other collectivist accounts of territory that are sensitive to history, see especially Nine (2012) and Moore (2015).

${ }^{4}$ These are addressed by Simmons on 119-20.

${ }^{5}$ I have discussed this question at greater length in relation to Locke in Miller (2009).

${ }^{6}$ To clarify, we might assume that when property-holders in a Lockean state of nature contract to create a political authority, they authorise the state to institutionalise strong property rights that (with few exceptions) are not subject to supersession. So these contracting citizens are no longer at liberty to take property that has ceased to feature in the plans and purposes of its legal owner. But outsiders who are not party to the contract are only obliged to respect the (more limited) moral rights of present owners, which, I have argued, are vulnerable to supersession.

7 Simmons concedes this point when discussing resource rights: 'states' property-like claims are strongest, the Lockean view argues, where they are claims to control the propertycreating or property-preserving activities of their own willing subjects. And states' claims are weakest where they are claims over things that are not used or actively pursued in their subjects' lives' (210).

${ }^{8}$ This view is spelt out more fully in Miller (2012).

${ }^{9}$ One might add a fourth: nationalist theories fail to explain how states are entitled to control and benefit from the unimproved natural resources that may be found on their territory. But as Simmons readily accepts, the Lockean theory too fails to justify the full set of resource rights that contemporary states invariably claim for themselves, including, for example rights over air space and resources buried deep in the ground, and he regards that as a virtue of the theory, rather than a vice. So it is not clear to me why he should regard it as a failing of nationalist theory if indeed it turns out that it can only justify a more limited set of resource rights. 
${ }^{10}$ In his discussion of rights supersession, Simmons notes that in law 'prescription' - gaining rights in things, including land, by long, uninterrupted possession - can be used to defeat the claims of the original possessor, but he treats this as a matter of administrative convenience with no moral basis (154-156). It seems to me more plausible, however, to regard the balance struck by law - which is of very long standing, harking back to Roman law - as reflecting a moral consensus on the relative weights of the claims of the two parties.

${ }^{11}$ I have discussed one such case in some detail in Miller (2014).

\section{References}

Altman A and Wellman C (2009) A Liberal Theory of International Justice. New York: Oxford University Press.

Beran H (1984) A Liberal Theory of Secession. Political Studies, 32(1): 21-31.

Gans C (2002) The Limits of Nationalism. Cambridge: Cambridge University Press.

Meisels T (2009) Territorial Rights. Dordrecht: Springer.

Miller D (2009) Property and Territory: Locke, Kant, and Steiner. Journal of Political Philosophy, 19(1): 90-109.

Miller D (2012) Territorial Rights: Concept and Justification. Political Studies, 60(2): 252-68.

Miller D (2014) Debatable Lands. International Theory, 6(1): 104-21.

Miller D (2016) Neo-Kantian Theories of Self-Determination: A Critique. Review of International Studies, 42(5): 858-75.

Moore M (2015) A Political Theory of Territory. New York: Oxford University Press.

Nine C (2012) Global Justice and Territory. Oxford: Oxford University Press.

Nozick R (1974) Anarchy, State and Utopia. Oxford: Blackwell. 
Simmons AJ (1992) The Lockean Theory of Rights. Princeton, NJ: Princeton University Press.

Simmons AJ (2010) Ideal and Nonideal Theory. Philosophy and Public Affairs, 38(1): 5-36.

Simmons AJ (2016) Boundaries of Authority. New York: Oxford University Press.

Steiner H (1996) Territorial Justice. In: Caney S, George D and Jones P (eds) National Rights, International Obligations. Boulder, CO: Westview Press, pp. 139-48.

Stilz A (2009) Why do States have Territorial Rights?. International Theory, 1(2): 185-213.

Stilz A (2011) Nations, States, and Territory. Ethics, 121(3): 572-601.

Valentini L (2012) Ideal vs Non-ideal Theory: A Conceptual Map. Philosophy Compass, 7(9): 654-664.

Waldron J (1992) Superseding Historic Injustice. Ethics, 103(1): 4-28.

Waldron J (1993) Special Ties and Natural Duties. Philosophy and Public Affairs, 22(1): 3-30.

Waldron J (2010) Two Conceptions of Self-Determination. In: Besson S and Tasioulas J (eds) The Philosophy of International Law. Oxford: Oxford University Press, pp. 397-413.

Ypi L (2014) A Permissive Theory of Territorial Rights. European Journal of Philosophy, 22(2): 288312.

\section{Author Biography}

David Miller is Professor of Political Theory and a Senior Research Fellow at Nuffield College, Oxford. He is currently co-editing books on refugees, and on national identity, and preparing a short book on self-determination for Polity. 